\title{
Implementable and ex-post IR rules in bilateral trading with discrete values
}

Citation for published version (APA):

Flesch, J., Schröder, M., \& Vermeulen, D. (2016). Implementable and ex-post IR rules in bilateral trading with discrete values. Mathematical Social Sciences, 84, 68-75.

https://doi.org/10.1016/j.mathsocsci.2016.08.003

Document status and date:

Published: 01/11/2016

DOI:

10.1016/j.mathsocsci.2016.08.003

Document Version:

Publisher's PDF, also known as Version of record

Document license:

Taverne

Please check the document version of this publication:

- A submitted manuscript is the version of the article upon submission and before peer-review. There can be important differences between the submitted version and the official published version of record.

People interested in the research are advised to contact the author for the final version of the publication, or visit the DOI to the publisher's website.

- The final author version and the galley proof are versions of the publication after peer review.

- The final published version features the final layout of the paper including the volume, issue and page numbers.

Link to publication

\footnotetext{
General rights rights.

- You may freely distribute the URL identifying the publication in the public portal. please follow below link for the End User Agreement:

www.umlib.nl/taverne-license

Take down policy

If you believe that this document breaches copyright please contact us at:

repository@maastrichtuniversity.nl

providing details and we will investigate your claim.
}

Copyright and moral rights for the publications made accessible in the public portal are retained by the authors and/or other copyright owners and it is a condition of accessing publications that users recognise and abide by the legal requirements associated with these

- Users may download and print one copy of any publication from the public portal for the purpose of private study or research.

- You may not further distribute the material or use it for any profit-making activity or commercial gain

If the publication is distributed under the terms of Article $25 \mathrm{fa}$ of the Dutch Copyright Act, indicated by the "Taverne" license above, 


\title{
Implementable and ex-post IR rules in bilateral trading with discrete values
}

\author{
János Flesch, Marc Schröder, Dries Vermeulen* \\ Department of Quantitative Economics, Maastricht University, P.O. Box 616, 6200 MD Maastricht, The Netherlands
}

\section{H I G H L I G H T S}

- We consider a bilateral trade model with a finite number of valuations.

- In this setting the classic impossibility result may be avoided.

- We illustrate the difference between interim- and ex post-implementation.

- For threshold trading rules, ex post-implementation equals posted price implementation.

\section{A R T I C L E I N F O}

\section{Article history:}

Received 27 October 2015

Received in revised form

2 August 2016

Accepted 15 August 2016

Available online 16 September 2016

\begin{abstract}
A B S T R A C T
We study bargaining problems between one buyer and one seller for a single object when each set of valuations is finite. We derive a necessary and sufficient condition for interim-implementable trading rules, analogous to the result in Myerson and Satterthwaite (1983), and a necessary condition for mechanisms that are free from ex post regret on and off equilibrium path. Based on these two theorems, our contribution is three-fold. First, we illustrate the results by means of three examples. Second, in contrast to the continuous model, there always exist strictly positive probability mass functions such that ex post efficiency and interim-implementability is feasible. Third, we show the difference between interim- and ex post-implementation. In the class of threshold trading rules, interim-implementation only precludes inefficient trade, while ex post-implementation is equivalent to posted price implementation.
\end{abstract}

(C) 2016 Elsevier B.V. All rights reserved.

\section{Introduction}

The bargaining problem with one buyer, one seller, a single object and two-sided incomplete information has attracted a lot of attention since the impossibility result of Myerson and Satterthwaite (1983). Their main theorem says that there exists no mechanism in which both players have an incentive to report truthfully, are willing to participate and that is ex post efficient, unless some outside party is willing to subsidize. The result is in contrast to some of the positive results in economics that were known in the literature at that time. In particular to the famous Coase' theorem, Coase (1960), that states that if transaction costs are sufficiently low, bargaining will lead to an efficient outcome regardless of the initial allocation. Other positive results include the First Fundamental Theorem of Welfare Economics, which states that market equilibria are Pareto

\footnotetext{
* Corresponding author.

E-mail addresses: j.flesch@maastrichtuniversity.nl (J. Flesch), m.schroeder@maastrichtuniversity.nl (M. Schröder), d.vermeulen@maastrichtuniversity.nl (D. Vermeulen).
}

efficient under the assumption of complete markets and price taking behaviour, and the VCG mechanism, that finds an efficient allocation in the setting with multiple buyers and one-sided incomplete information.

One of the assumptions in Myerson and Satterthwaite (1983), and in many related papers, is that valuations are continuously distributed over overlapping intervals with positive density. However, there does not seem to be a compelling modelling reason to prefer continuous type spaces to discrete ones (Vohra, 2011). In many applications, for example in monetary transactions, agents typically reason with a limited amount of possible valuations. The assumption of a positive density is crucial for the impossibility result, as Myerson and Satterthwaite (1983) already provide an example with a simple discrete setting, two types for each player, for which the non-existence result does not hold. Matsuo (1989) elaborates on this example by characterizing the condition under which ex post efficient trade is feasible if both players have two types. We focus on bilateral trading with finite sets of valuations, similar to recent work like Kos and Manea (2009) and Othman and Sandholm (2009), and show the importance of the assumption of continuous valuations for the impossibility 
result. We find that for every set of discrete valuations, there exist probability mass functions such that ex post efficiency and interimimplementability is feasible.

Myerson and Satterthwaite (1983) consider the condition interim individual rationality, meaning that each player's expected utility conditional on his type is non-negative. This allows the use of mechanisms in which, for example, a type of buyer is required to make a payment while trade does not take place. In most markets this does not occur, since ex post enforcement of payment is usually not feasible when the terms of trade lead to loss of utility. We focus on mechanisms that are free from ex post regret on and off equilibrium path. We use an idea from Matthews and Postlewaite (1989), in which players have the option to opt out of the mechanism after the mechanism is played and the outcome is revealed. This additional option gives players the possibility to guarantee the outside utility of zero. In order to illustrate the difference between the two conditions, we consider the class of threshold trading rules. All trading rules within this class that preclude inefficient trade are interim-implementable, while ex post individually rational trading rules can only be implemented by means of a posted price mechanism. Thus, ex post-implementation selects the posted price mechanisms from among all threshold trading rules that avoid inefficient trade.

Related literature. We briefly outline the papers closely related to ours. In a setting with one seller, multiple buyers, a single object and one-sided incomplete information, Myerson (1981) characterizes the auction that maximizes the expected revenue for the seller.

Next, we consider the setting with one seller, one buyer, a single object and two-sided incomplete information. Myerson and Satterthwaite (1983) show that there is no mechanism that is budgetbalanced, incentive compatible, interim individually rational and ex post efficient. They also derive a characterization of the incentive compatible mechanism that maximizes the expected gains from trade. Hagerty and Rogerson (1987) show that if a mechanism is dominant strategy incentive compatible and ex post individually rational, then it is a posted price mechanism. Matsuo (1989) assumes that both players have two types and presents a necessary and sufficient condition for ex post efficient mechanisms to be feasible. Gresik (1991b) identifies the mechanism that maximizes the expected gains from trade for regular probability distributions. He also shows that, when the probability distributions are regular and unimodular, this mechanism is incentive compatible and ex post individually rational. For uniform probability distributions, the identified mechanism coincides with the linear equilibrium in Chatterjee and Samuelson (1983). Gresik (1991a) assumes that both players have two types and statistically dependent beliefs. He derives a necessary and sufficient condition for ex post efficient trade to be feasible. Kos and Manea (2009) introduce a modification of the VCG mechanism, and show that there exists an incentive compatible, interim individually rational and efficient mechanism if and only if the modified VCG mechanism does not run a deficit. Othman and Sandholm (2009) run simulations with discrete valuations to check how often efficient trade can be obtained. Garratt and Pycia (2016) show that efficient trade is generically possible if the assumption of quasi-linear utilities is relaxed and the utilities are not too responsive to private information.

Matthews and Postlewaite (1989) introduce the model with quitting rights for players, also called veto rights in the literature. The idea is that players have the right to reject the trade after the outcome of the mechanism. Forges (1999) extends this idea to multiple buyers. Compte and Jehiel (2009) show that in their bargaining model with ex post quitting rights and correlations, inefficiencies are inevitable. Galavotti et al. (2011) discuss the possibility of efficient partnership dissolution with ex post quitting rights.

The organization of the paper is as follows. Section 2 introduces the model. The two theorems on interim-implementation and ex post-implementation with illustrating examples are given in Section 3. Section 4 studies the class of ex post efficient trading rules and the class of threshold trading rules. Section 5 concludes. Some of the proofs are relegated to the Appendix.

\section{The model}

Consider the following discrete bilateral trade model in which two players, a buyer and a seller, bargain under incomplete information. The seller currently owns an indivisible object that the buyer is willing to buy. Let the buyer have valuations drawn from a discrete set $V_{b}=\left\{b_{1}, \ldots, b_{m}\right\}$, where $0 \leq b_{1}<\cdots<b_{m}$, and the seller have valuations drawn from a discrete set $V_{s}=$ $\left\{s_{1}, \ldots, s_{n}\right\}$, where $0 \leq s_{1}<\cdots<s_{n}$. We assume the standard independent private values information structure. The valuations of the two agents are independently distributed random variables, with probability mass functions $f_{b}: V_{b} \rightarrow[0,1]$ such that $\sum_{i=1}^{m} f_{b}\left(b_{i}\right)=1$ and $f_{s}: V_{s} \rightarrow[0,1]$ such that $\sum_{j=1}^{m} f_{s}\left(s_{j}\right)=1$. Let $F_{b}: \mathbb{R} \rightarrow[0,1]$ be the cumulative distribution corresponding to $f_{b}, F_{b}(v)=\sum_{b_{i}<v} f_{b}\left(b_{i}\right)$, and $F_{s}: \mathbb{R} \rightarrow[0,1]$ the cumulative distribution corresponding to $f_{s}, F_{s}(v)=\sum_{s_{j} \leq v} f_{s}\left(s_{j}\right)$.

The bargaining process is modelled by a direct mechanism. A direct bargaining mechanism is a mechanism in which each player simultaneously reports a valuation to a coordinator. The coordinator will then determine whether the object is traded and what the transfer will be. Without loss of generality we can concentrate on direct mechanisms due to the revelation principle. The revelation principle says that for any Bayesian equilibrium in any bargaining game, there exists an equivalent direct mechanism yielding the same outcome (both an equivalent allocation and payment) in which truthful reporting is a Bayesian equilibrium. Accordingly, we can mimic any equilibrium in any bargaining mechanism by a direct mechanism.

Formally, a direct mechanism is a pair of functions $(q, t)$,

$q: V_{b} \times V_{s} \rightarrow[0,1]$,

$t: V_{b} \times V_{s} \rightarrow \mathbb{R}$

where $q\left(b_{i}, s_{j}\right)$ is the probability that the object is traded and $t\left(b_{i}, s_{j}\right)$ is the transfer of the buyer to the seller, when $b_{i} \in V_{b}$ and $s_{j} \in V_{s}$ are the reported valuations. We refer to $q$ as the trading rule, and $t$ as the transfer scheme.

Notation. Given a direct mechanism $(q, t)$, we write

$$
\begin{aligned}
\bar{q}_{b}\left(b_{i}\right) & =\sum_{j=1}^{n} q\left(b_{i}, s_{j}\right) \cdot f_{s}\left(s_{j}\right), \\
\bar{t}_{b}\left(b_{i}\right) & =\sum_{j=1}^{n} t\left(b_{i}, s_{j}\right) \cdot f_{s}\left(s_{j}\right), \\
\bar{q}_{s}\left(s_{j}\right) & =\sum_{i=1}^{m} q\left(b_{i}, s_{j}\right) \cdot f_{b}\left(b_{i}\right), \\
\bar{t}_{s}\left(s_{j}\right) & =\sum_{i=1}^{m} t\left(b_{i}, s_{j}\right) \cdot f_{b}\left(b_{i}\right) .
\end{aligned}
$$

Thus $\bar{q}_{b}\left(b_{i}\right)$ and $\bar{t}_{b}\left(b_{i}\right)$ are the expected probability of trade and the expected transfer, respectively, for a buyer reporting $b_{i} \in V_{b}$, given that the seller reports truthfully. Analogous for the seller. 


\section{Interim-implementation and ex post-implementation with quitting rights}

In most of the literature, the expected utility of a player is defined as follows. For a given direct mechanism $(q, t)$, define the expected utility of a buyer reporting $b_{k} \in V_{b}$ when having valuation $b_{i} \in V_{b}$ and the expected utility of a seller reporting $s_{\ell} \in V_{s}$ when having valuation $s_{j} \in V_{s}$, given that the other player reports truthfully, by

$U_{b}\left(b_{k}, b_{i}\right)=b_{i} \cdot \bar{q}_{b}\left(b_{k}\right)-\bar{t}_{b}\left(b_{k}\right)$,

$U_{s}\left(s_{\ell}, s_{j}\right)=\bar{t}_{s}\left(s_{\ell}\right)-s_{j} \cdot \bar{q}_{s}\left(s_{\ell}\right)$.

The focus of this paper is on mechanisms that are free from ex post regret. We assume that after the mechanism has been played and the outcome of the mechanism is revealed, each player has the option to refuse the outcome of the mechanism and receive an outside utility of zero. This idea is introduced in Matthews and Postlewaite (1989). For a given direct mechanism $(q, t)$ with quitting rights, define the expected utility of a buyer reporting $b_{k} \in V_{b}$ when having valuation $b_{i} \in V_{b}$ and the expected utility of a seller reporting $s_{\ell} \in V_{s}$ when having valuation $s_{j} \in V_{s}$, given that the other player reports truthfully, by

$U_{b}^{*}\left(b_{k}, b_{i}\right)=\sum_{j=1}^{n} \max \left\{0, b_{i} \cdot q\left(b_{k}, s_{j}\right)-t\left(b_{k}, s_{j}\right)\right\} \cdot f_{s}\left(s_{j}\right)$,

$U_{s}^{*}\left(s_{\ell}, s_{j}\right)=\sum_{i=1}^{m} \max \left\{0, t\left(b_{i}, s_{\ell}\right)-s_{j} \cdot q\left(b_{i}, s_{\ell}\right)\right\} \cdot f_{b}\left(b_{i}\right)$.

The max operator in $U^{*}$ represents the possibility to reject the trade ex post.

Definition 3.1. A direct mechanism $(q, t)$ is incentive compatible (IC) if for all $b_{i}, b_{k} \in V_{b}$ and all $s_{j}, s_{\ell} \in V_{s}$

$U_{b}\left(b_{i}, b_{i}\right) \geq U_{b}\left(b_{k}, b_{i}\right)$ and $U_{s}\left(s_{j}, s_{j}\right) \geq U_{s}\left(s_{\ell}, s_{j}\right)$.

A direct mechanism $(q, t)$ is incentive compatible with quitting rights (IC*) if for all $b_{i}, b_{k} \in V_{b}$ and all $s_{j}, s_{\ell} \in V_{s}$

$U_{b}^{*}\left(b_{i}, b_{i}\right) \geq U_{b}^{*}\left(b_{k}, b_{i}\right)$ and $U_{s}^{*}\left(s_{j}, s_{j}\right) \geq U_{s}^{*}\left(s_{\ell}, s_{j}\right)$.

The above two conditions guarantee that truthful reporting is a Bayesian Nash equilibrium in the two respective settings.

Much work in the literature is concerned with interim individual rationality, while in the present study, we are interested in mechanisms that satisfy ex post individual rationality.

Definition 3.2. A direct mechanism $(q, t)$ is interim individually rational (IIR) if for all $b_{i} \in V_{b}$ and all $s_{j} \in V_{s}$

$U_{b}\left(b_{i}, b_{i}\right) \geq 0$ and $U_{s}\left(s_{j}, s_{j}\right) \geq 0$.

A direct mechanism $(q, t)$ is ex post individually rational (EPIR) if for all $b_{i} \in V_{b}$ and all $s_{j} \in V_{s}$

$b_{i} \cdot q\left(b_{i}, s_{j}\right)-t\left(b_{i}, s_{j}\right) \geq 0$ and $t\left(b_{i}, s_{j}\right)-s_{j} \cdot q\left(b_{i}, s_{j}\right) \geq 0$.

A mechanism is interim individually rational if on the equilibrium path, given his type, but before he learns the other player's type, each player prefers to participate in the mechanism over the outside option. A mechanism is ex post individually rational if on the equilibrium path, for any realization of types, no player regrets his participation in the mechanism even after observing the realized values.

A trading rule $q$ is interim-implementable if there exists a transfer scheme $t$ such that $(q, t)$ is IC and IIR. A trading rule $q$ is ex post-implementable if there exists a transfer scheme $t$ such that $(q, t)$ is IC and EPIR. A trading rule $q$ is ex post-implementable with quitting rights if there exists a transfer scheme $t$ such that $(q, t)$ is IC ${ }^{*}$ and EPIR.

Given a trading rule $q$, we define the following quantities

$$
\begin{aligned}
l_{b}= & \sum_{j=1}^{n} s_{j} \cdot q\left(b_{1}, s_{j}\right)-b_{1} \cdot \bar{q}_{b}\left(b_{1}\right) \cdot\left(1-F_{b}\left(b_{1}\right)\right) \\
& +\sum_{i=2}^{m}\left(b_{i-1} \cdot\left(1-F_{b}\left(b_{i-1}\right)\right)-b_{i} \cdot\left(1-F_{b}\left(b_{i}\right)\right)\right) \cdot \bar{q}_{b}\left(b_{i}\right), \\
u_{b}= & \sum_{i=1}^{m}\left(b_{i} \cdot\left(1-F_{b}\left(b_{i-1}\right)\right)-b_{i+1} \cdot\left(1-F_{b}\left(b_{i}\right)\right)\right) \cdot \bar{q}_{b}\left(b_{i}\right), \\
l_{s}= & \sum_{j=1}^{n}\left(s_{j} \cdot F_{s}\left(s_{j}\right)-s_{j-1} \cdot F_{s}\left(s_{j-1}\right)\right) \cdot \bar{q}_{s}\left(s_{j}\right), \\
u_{s}= & \sum_{j=1}^{n-1}\left(s_{j+1} \cdot F_{s}\left(s_{j}\right)-s_{j} \cdot F_{s}\left(s_{j-1}\right)\right) \cdot \bar{q}_{s}\left(s_{j}\right) \\
& -s_{n} \cdot F_{s}\left(s_{n-1}\right) \cdot \bar{q}_{s}\left(s_{n}\right)+\sum_{i=1}^{m} b_{i} \cdot q\left(b_{i}, s_{n}\right) .
\end{aligned}
$$

Observe that $u_{b}$ and $l_{s}$ include the buyer's and seller's virtual valuation, respectively. For an economic interpretation of these quantities, we refer to Bulow and Roberts (1989) and Kos and Manea (2009).

The first result is the characterization of an interim-implementable trading rule, analogous to the result in Myerson and Satterthwaite (1983).

Theorem 3.3. A trading rule $q$ is interim-implementable if and only if $\bar{q}_{b}\left(b_{i}\right)$ is non-decreasing in $b_{i}, \bar{q}_{s}\left(s_{j}\right)$ is non-increasing in $s_{j}$, and $l_{s} \leq u_{b}$

The second result provides a necessary condition for a trading rule that is ex post-implementable with quitting rights.

Theorem 3.4. If a direct mechanism $(q, t)$ is $I C^{*}$ and EPIR, then

$l_{b} \leq \sum_{i=0}^{m} \sum_{j=0}^{n} t\left(b_{i}, s_{j}\right) \cdot f_{b}\left(b_{i}\right) \cdot f_{s}\left(s_{j}\right) \leq u_{s}$.

Consequently, if a trading rule $q$ is ex post-implementable with quitting rights, then $l_{b} \leq u_{s}$.

Proof. Suppose $(q, t)$ is IC* and EPIR. We only show that

$\sum_{i=1}^{m} \sum_{j=1}^{n} t\left(b_{i}, s_{j}\right) \cdot f_{b}\left(b_{i}\right) \cdot f_{s}\left(s_{j}\right) \leq u_{s}$.

For each seller with a valuation of $s_{j}$ for $j=1, \ldots, n-1$, IC implies

$\bar{t}_{s}\left(s_{j}\right)-\bar{t}_{s}\left(s_{j+1}\right) \leq s_{j+1} \cdot\left(\bar{q}_{s}\left(s_{j}\right)-\bar{q}_{s}\left(s_{j+1}\right)\right)$.

By adding all these inequalities for $\ell=j, \ldots, n-1$, we get

$\bar{t}_{s}\left(s_{j}\right)-\bar{t}_{s}\left(s_{n}\right) \leq \sum_{\ell=j}^{n-1} s_{\ell+1} \cdot\left(\bar{q}_{s}\left(s_{\ell}\right)-\bar{q}_{s}\left(s_{\ell+1}\right)\right)$.

By EPIR, we have $\bar{t}_{s}\left(s_{n}\right) \leq \sum_{i=1}^{m} b_{i} \cdot q\left(b_{i}, s_{n}\right)$ and thus

$\bar{t}_{s}\left(s_{j}\right) \leq \sum_{\ell=j}^{n-1} s_{\ell+1} \cdot\left(\bar{q}_{s}\left(s_{\ell}\right)-\bar{q}_{s}\left(s_{\ell+1}\right)\right)+\sum_{i=1}^{m} b_{i} \cdot q\left(b_{i}, s_{n}\right)$. 
Adding the inequalities of (1) over all $s_{j}$ and weighting by $f_{s}\left(s_{j}\right)$ yields

$$
\begin{aligned}
& \sum_{i=1}^{m} \sum_{j=1}^{n} t\left(b_{i}, s_{j}\right) \cdot f_{b}\left(b_{i}\right) \cdot f_{s}\left(s_{j}\right) \\
& \leq \sum_{j=1}^{n-1}\left(\sum_{\ell=j}^{n-1} s_{\ell+1} \cdot\left(\bar{q}_{s}\left(s_{\ell}\right)-\bar{q}_{s}\left(s_{\ell+1}\right)\right)\right. \\
& \left.\quad+\sum_{i=1}^{m} b_{i} \cdot q\left(b_{i}, s_{n}\right)\right) \cdot f_{s}\left(s_{j}\right)+\sum_{i=1}^{m} b_{i} \cdot q\left(b_{i}, s_{n}\right) \\
& =\sum_{j=1}^{n-1}\left(s_{j+1} \cdot F_{s}\left(s_{j}\right)-s_{j} \cdot F_{s}\left(s_{j-1}\right)\right) \cdot \bar{q}_{s}\left(s_{j}\right) \\
& \quad-s_{n} \cdot F_{s}\left(s_{n-1}\right) \cdot \bar{q}_{s}\left(s_{n}\right)+\sum_{i=1}^{m} b_{i} \cdot q\left(b_{i}, s_{n}\right) \\
& =u_{s} .
\end{aligned}
$$

This completes the proof.

Remark. The result of Theorem 3.4 also applies if $(q, t)$ is IC and EPIR.

In the upcoming three examples, we illustrate the following three facts.

(1) The conditions of Theorems 3.3 and 3.4 do not characterize ex post-implementation with quitting rights.

(2) Ex post-implementation with quitting rights is not equivalent to ex post-implementation.

(3) The choice of valuations in the set of valuations matters for implementation. We give an example in which if we consider a valuation with a probability of zero, implementation is not feasible, while if we not consider that valuation, implementation is feasible.

Example 3.5. We provide an example of a trading rule for which $\bar{q}_{b}\left(b_{i}\right)$ is non-decreasing in $b_{i}, \bar{q}_{s}\left(s_{j}\right)$ is non-increasing in $s_{j}, l_{s} \leq$ $u_{b}$, and $l_{b} \leq u_{s}$, but which is not ex post-implementable with quitting rights. So, Theorem 3.4 does not characterize ex postimplementation with quitting rights.

Let $V_{b}=V_{s}=\{0,1,2,3,4,5,6,7,8\}$ and assume that the valuations are uniformly distributed. Consider Trading rule 2 below.

\begin{tabular}{c|ccccccccc} 
& 0 & 1 & 2 & 3 & 4 & 5 & 6 & 7 & 8 \\
\hline 0 & 0 & 0 & 0 & 0 & 0 & 0 & 0 & 0 & 0 \\
1 & 0 & 0 & 0 & 0 & 0 & 0 & 0 & 0 & 0 \\
2 & 0 & 0 & 0 & 0 & 0 & 0 & 0 & 0 & 0 \\
3 & 0 & 0 & 0 & 0 & 0 & 0 & 0 & 0 & 0 \\
4 & 0 & 0 & 0 & 0 & 0 & 0 & 0 & 0 & 0 \\
5 & 1 & 0 & 0 & 0 & 0 & 0 & 0 & 0 & 0 \\
6 & 1 & 0 & 0 & 0 & 0 & 0 & 0 & 0 & 0 \\
7 & 1 & 0 & 0 & 0 & 0 & 0 & 0 & 0 & 0 \\
8 & 1 & 1 & 1 & 1 & 1 & 1 & 1 & 1 & 0
\end{tabular}

Denote Trading rule 2 by $q$. By definition of $l_{b}, u_{b}, l_{s}$ and $u_{s}$, we have $l_{b}=\frac{65}{81}, u_{b}=\frac{76}{81}, l_{s}=\frac{56}{81}$ and $u_{s}=\frac{67}{81}$. Hence, $l_{s} \leq u_{b}$ and $l_{b} \leq u_{s}$.

We show that Trading rule 1 is not ex post-implementable with quitting rights. Suppose $t$ is a transfer scheme such that $(q, t)$ is $I^{*}$ and EPIR. We derive a contradiction. On the one hand, the constraint $U_{s}^{*}(1,1) \geq U_{s}^{*}(0,1)$ yields $\sum_{i=5}^{8} t(i, 0) \leq t(8,1)+3$. Since $(q, t)$ is EPIR, we know that $t(8,1) \leq 8$. Thus,

$\sum_{b=5}^{8} t\left(b_{i}, 0\right) \leq t(8,1)+3 \leq 8+3=11$.

On the other hand, the constraints $U_{b}^{*}(5,5) \geq U_{b}^{*}(4,5), U_{b}^{*}(6,6) \geq$ $U_{b}^{*}(4,6)$ and $U_{b}^{*}(7,7) \geq U_{b}^{*}(4,7)$ yield

$\sum_{b=5}^{7} t\left(b_{i}, 0\right) \geq 12$.

Since $t(8,0) \geq 0$ by EPIR, we derived a contradiction.

Example 3.6. This example provides a trading rule $t$ which is ex post-implementable, but not ex post-implementable with quitting rights.

Let $V_{b}=V_{s}=\{0,1,2,3,4,5,6,7,8\}$ and assume that the valuations are uniformly distributed. Consider Trading rule 3 below.

\begin{tabular}{c|ccccccccc} 
& 0 & 1 & 2 & 3 & 4 & 5 & 6 & 7 & 8 \\
\hline 0 & 0 & 0 & 0 & 0 & 0 & 0 & 0 & 0 & 0 \\
1 & 0 & 0 & 0 & 0 & 0 & 0 & 0 & 0 & 0 \\
2 & 0 & 0 & 0 & 0 & 0 & 0 & 0 & 0 & 0 \\
3 & 0 & 0 & 0 & 0 & 0 & 0 & 0 & 0 & 0 \\
4 & 0 & 0 & 0 & 0 & 0 & 0 & 0 & 0 & 0 \\
5 & 0 & 0 & 0 & 0 & 0 & 0 & 0 & 0 & 0 \\
6 & 1 & 0 & 0 & 0 & 0 & 0 & 0 & 0 & 0 \\
7 & 1 & 0 & 0 & 0 & 0 & 0 & 0 & 0 & 0 \\
8 & 1 & 1 & 1 & 1 & 1 & 1 & 1 & 1 & 0
\end{tabular}

\begin{tabular}{c|ccccccccc} 
& 0 & 1 & 2 & 3 & 4 & 5 & 6 & 7 & 8 \\
\hline 0 & 0 & 0 & 0 & 0 & 0 & 0 & 0 & 0 & 0 \\
1 & 0 & 0 & 0 & 0 & 0 & 0 & 0 & 0 & 0 \\
2 & 0 & 0 & 0 & 0 & 0 & 0 & 0 & 0 & 0 \\
3 & 0 & 0 & 0 & 0 & 0 & 0 & 0 & 0 & 0 \\
4 & 0 & 0 & 0 & 0 & 0 & 0 & 0 & 0 & 0 \\
5 & 0 & 0 & 0 & 0 & 0 & 0 & 0 & 0 & 0 \\
6 & 5 & 0 & 0 & 0 & 0 & 0 & 0 & 0 & 0 \\
7 & 5 & 0 & 0 & 0 & 0 & 0 & 0 & 0 & 0 \\
8 & 0 & 8 & 8 & 8 & 8 & 8 & 8 & 8 & 0 \\
& \multicolumn{8}{|c}{ Transfer scheme $t^{\prime}}$. &
\end{tabular}

Denote Trading rule 3 by $q$. Define $t^{\prime}$ as above. Then $\left(q, t^{\prime}\right)$ is IC and EPIR. However, $\left(q, t^{\prime}\right)$ is not IC $\mathrm{IC}^{*}$, since $U_{b}^{*}(7,7)<U_{b}^{*}(8,7)$.

We show that there is no $t$ such that $(q, t)$ is IC* and EPIR. Let $t$ be such that $(q, t)$ is IC* and EPIR. By IC* for the buyer, $t(6,0)=$ $t(7,0) \geq 5$, respectively. By IC* for the seller, $7 \leq t(8,1)=\cdots=$ $t(8,7) \leq 8$. This implies that a buyer with $b_{i}=7$ reporting $b_{i}^{\prime}=8$ will reject all trade with each seller $s_{j}$ with $1 \leq s_{j} \leq 7$. Hence $U_{b}^{*}(7,7) \geq U_{b}^{*}(8,7)$ implies $t(8,0) \geq t(7,0)$. This implies that

$$
\begin{aligned}
U_{s}^{*}(0,1) & =\frac{t(6,0)+t(7,0)+t(8,0)-3}{9} \geq \frac{12}{9}>\frac{t(8,1)-1}{9} \\
& =U_{s}^{*}(1,1),
\end{aligned}
$$

which contradicts with the constraints of IC* 


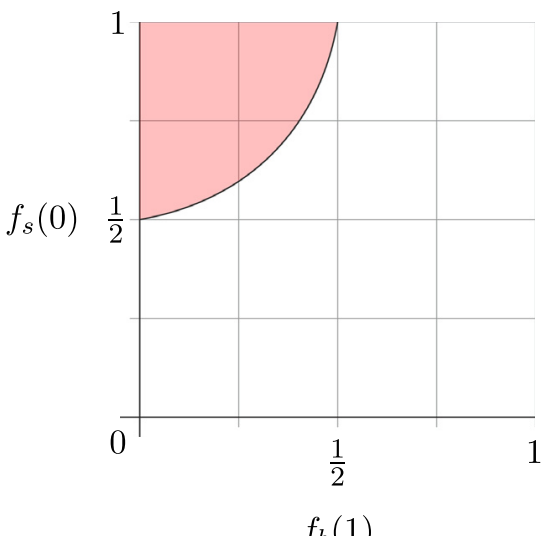

$f_{b}(1)$

Fig. 1. The shaded area is not implementable.

Example 3.7. This example shows that the existence of a valuation with probability zero matters for implementability. ${ }^{1}$ In the example, the choice of considering a valuation with probability zero or not considering that valuation, determines whether the trading rule is implementable.

Let $V_{b}=\{1,3\}$ and $V_{s}=\{0,2\}$. Consider Trading rule 1 below.

\begin{tabular}{c|cc} 
& 0 & 2 \\
\hline 1 & 1 & 0 \\
3 & 1 & 1 \\
\multicolumn{2}{c}{ Trading rule 1.}
\end{tabular}

Denote Trading rule 1 by $q$. The proofs in Matsuo (1989) show that if $m=n=2$, interim-implementation and ex postimplementation with quitting rights are equivalent. By definition of $l_{b}, u_{b}, l_{s}$ and $u_{s}$, and $f_{b}(1)+f_{b}(3)=1$ and $f_{2}(0)+f_{2}(2)=1$, we have

$$
\begin{aligned}
l_{b} & =\left(1-f_{b}(1)\right) \cdot\left(1-f_{s}(0)\right), \\
u_{b} & =f_{s}(0)+3 \cdot\left(1-f_{b}(1)\right) \cdot\left(1-f_{s}(0)\right), \\
l_{s} & =2 \cdot\left(1-f_{b}(1)\right), \\
u_{s} & =3 \cdot\left(1-f_{b}(1)\right)+2 \cdot f_{b}(1) \cdot f_{s}(0) .
\end{aligned}
$$

Observe that $l_{b} \leq u_{s}$ for all $f_{b}(1)$ and $f_{s}(0)$. By Theorem 3.3, $q$ is interim implementable and ex post-implementable with quitting rights if and only if

$$
1-f_{b}(1)-2 \cdot f_{s}(0)+3 \cdot f_{b}(1) \cdot f_{s}(0) \geq 0 .
$$

From Fig. 1, we can see that if $0 \leq f_{b}(1)<\frac{1}{2}$ and $f_{s}(0)=$ $1, q$ is not ex post-implementable with quitting rights. However, it is clear that if $V_{s}=\{0\}$, a posted price in between 0 and 1 guarantees IC*, EPIR and ex post efficiency. So the question which valuations to include into the set of valuations can have important consequences.

\section{Two classes of trading rules}

This section analyses two specific subclasses of trading rules: ex post efficient trading rules and threshold trading rules. These subclasses of trading rules only contain rules that are deterministic and monotone. A trading rule $q$ is monotone if $q\left(b_{i}, s_{j}\right) \leq q\left(b_{k}, s_{\ell}\right)$ for all $b_{i} \leq b_{k} \in V_{b}$ and all $s_{j} \geq s_{\ell} \in V_{s}$. A trading rule $q$ is deterministic if $q\left(b_{i}, s_{j}\right) \in\{0,1\}$ for all $b_{i} \in V_{b}$ and all $s_{j} \in V_{s}$.

\footnotetext{
1 Othman and Sandholm (2009) use the same example as their motivating example.
}

It is known that the restriction of deterministic trading rules in general does not hamper the analysis, since for example second-best Pareto optimality can be established within this class of trading rules (e.g. Myerson and Satterthwaite, 1983; Gresik, 1991a). The advantage of this class of trading rules is that the expected probability of trade is automatically monotone. As a result, we do not need to add monotonicity properties for the expected probabilities of trade as separate requirements in the analysis. Moreover, Matthews and Postlewaite (1989) show that for the class of deterministic and monotone trading rules, ex postimplementability is equivalent to ex post-implementability with quitting rights if transfers are monotone.

Our main results are as follows. In the class of ex post efficient trading rules, we prove that there always exists strictly positive probability mass functions that guarantee interimimplementability. In the class of threshold trading rules, a trading rule is interim-implementable as soon as it does not allow inefficient trade, ${ }^{2}$ and ex post-implementable with quitting rights if the trading rule is posted price implementable. Thus, all reasonable threshold trading rules are interim-implementable, whereas ex post-implementability with quitting rights coincides with dominant strategy implementation (Hagerty and Rogerson, 1987).

\subsection{Ex post efficient trading rules}

From a social point of view it is optimal to have trade whenever the buyer values the object higher than the seller, and not to have trade whenever the seller values the object higher than the buyer. A trading rule $q$ is ex post efficient (EPE) if $q\left(b_{i}, s_{j}\right)=1$ whenever $b_{i}>s_{j}$ and $q\left(b_{i}, s_{j}\right)=0$ whenever $b_{i} \leq s_{j}$.

The famous impossibility result of Myerson and Satterthwaite (1983) only holds if valuations are continuously distributed with positive density on overlapping intervals. The following theorem shows that the impossibility result is not valid in the discrete setting. That is, there always exist probability mass functions such that ex post efficient and interim individually rational trade is feasible.

Theorem 4.1. Let $q$ be EPE. There exist strictly positive $f_{b}$ and $f_{s}$ such that $q$ is interim-implementable.

Proof. By Theorem 3.3, $q$ is interim-implementable if and only if $l_{s} \leq u_{b}$. For all $b_{i} \in V_{b}$ and all $s_{j} \in V_{s}$, define $s\left(b_{i}\right)=\max \left\{s_{\ell} \in V_{s} \mid\right.$ $\left.b_{i}>s_{\ell}\right\}$ and $b\left(s_{j}\right)=\min \left\{b_{k} \in V_{b} \mid b_{k}>s_{j}\right\}$. Observe that

$$
\begin{aligned}
l_{s}= & \sum_{j=1}^{n}\left(s_{j} \cdot F_{s}\left(s_{j}\right)-s_{j-1} \cdot F_{s}\left(s_{j-1}\right)\right) \cdot\left(1-F_{b}\left(s_{j}\right)\right) \\
= & \sum_{j=1}^{n}\left(\sum_{\ell=j}^{n-1} s_{\ell} \cdot\left(F_{b}\left(s_{\ell+1}\right)-F_{b}\left(s_{\ell}\right)\right)\right. \\
& \left.+s_{n} \cdot\left(1-F_{b}\left(s_{n}\right)\right)\right) \cdot f_{s}\left(s_{j}\right) \\
= & \sum_{i=1}^{m} \sum_{j=1}^{n} s\left(b_{i}\right) \cdot q\left(b_{i}, s_{j}\right) \cdot f_{b}\left(b_{i}\right) \cdot f_{s}\left(s_{j}\right)
\end{aligned}
$$

An analogous analysis holds for the buyer. So,

$$
l_{s} \leq u_{b} \Leftrightarrow \sum_{i=1}^{m} \sum_{j=1}^{n}\left(b\left(s_{j}\right)-s\left(b_{i}\right)\right) \cdot q\left(b_{i}, s_{j}\right) \cdot f_{b}\left(b_{i}\right) \cdot f_{s}\left(s_{j}\right) \geq 0 .
$$

\footnotetext{
2 A deterministic trading rule $q$ allows inefficient trade when $q\left(b_{i}, s_{j}\right)=1$ for some $b_{i} \in V_{b}$ and $s_{j} \in V_{s}$ with $b_{i}<s_{j}$.
} 
Let $b_{k} \in V_{b}$ be the minimum valuation of the buyer that has trade. More formally, $b_{k}=\min \left\{b_{i} \in V_{b} \mid b_{i}>s_{j}\right.$ for some $\left.s_{j} \in V_{s}\right\}$. If such valuation does not exist, $b_{m}<s_{1}$ and thus $q\left(b_{i}, s_{j}\right)=0$ for all $b_{i} \in V_{b}$ and all $s_{j} \in V_{s}$, which implies that $q$ is interimimplementable for every $f_{b}$ and $f_{s}$. Otherwise, define $f_{s}\left(s_{j}\right)=\frac{1}{n}$ for all $s_{j} \in V_{s}$. Notice that

$\sum_{j=1}^{n}\left(b\left(s_{j}\right)-s\left(b_{k}\right)\right) \cdot q\left(b_{i}, s_{j}\right) \cdot \frac{1}{n} \geq\left(b_{k}-s\left(b_{k}\right)\right) \cdot \frac{1}{n}>0$,

where the first inequality follows by definition of $b_{k}$. This implies that there exists a strictly positive probability density function $f_{b}$ with sufficiently high probability on $b_{k}$ such that

$\sum_{i=1}^{m} \sum_{j=1}^{n}\left(b\left(s_{j}\right)-s\left(b_{i}\right)\right) \cdot q\left(b_{i}, s_{j}\right) \cdot \frac{1}{n} \cdot f_{b}\left(b_{i}\right)>0$.

Hence the result follows.

\subsection{Threshold trading rules}

A trading rule $q$ is a threshold trading rule if there are $v_{b} \in V_{b}$ and $v_{s} \in V_{s}$ such that $q\left(b_{i}, s_{j}\right)=1$ whenever $b_{i} \geq v_{b}$ and $s_{j} \leq v_{s}$, and $q\left(b_{i}, s_{j}\right)=0$ otherwise.

A trading rule $q$ is posted price implementable if there is a transfer scheme $t$ such that there is a price $p>0$, where $t\left(b_{i}, s_{j}\right)=p$ with $s_{j} \leq p \leq b_{i}$ whenever $q\left(b_{i}, s_{j}\right)=1$, and $t\left(b_{i}, s_{j}\right)=0$ otherwise. In a posted price mechanism, a transfer is only made when trade occurs, and the size of the transfer is exactly $p$.

In the class of threshold trading rules, ex post-implementation with quitting rights is equivalent to posted price implementation.

Theorem 4.2. Let $q$ be a threshold trading rule, characterized by $v_{b}$ and $v_{s}$. Then

(i) $q$ is interim-implementable if and only if $v_{b} \geq v_{s}$.

(ii) $q$ is ex post-implementable with quitting rights if and only if $q$ is posted price implementable.

Proof. For (i). By Theorem 3.3, $q$ is interim-implementable if and only if $l_{s} \leq u_{b}$. By definition of $l_{s}$ and $u_{b}$, we have

$l_{s} \leq u_{b} \Leftrightarrow v_{s} \cdot\left(1-F_{b}\left(v_{b-1}\right)\right) \cdot F_{s}\left(v_{s}\right) \leq v_{b} \cdot\left(1-F_{b}\left(v_{b-1}\right)\right) \cdot F_{s}\left(v_{s}\right)$

For (ii). Suppose $q$ is ex post-implementable with quitting rights. Then $q$ is interim-implementable. So by (i), $v_{b} \geq v_{s}$. If $v_{b}=$ $b_{1}$, setting $p=v_{s}$ shows that $q$ is posted price implementable. If $v_{s}=s_{n}$, setting $p=v_{b}$ shows that $q$ is posted price implementable. If $v_{b}>b_{1}$ and $v_{s}<s_{n}$, then by Theorem 3.4, $l_{b} \leq u_{s}$. By definition of $l_{b}$ and $u_{s}$, we have

$$
\begin{aligned}
l_{b} & \leq u_{s} \Leftrightarrow v_{b-1} \cdot\left(1-F_{b}\left(v_{b-1}\right)\right) \cdot F_{s}\left(v_{s}\right) \\
& \leq v_{s+1} \cdot\left(1-F_{b}\left(v_{b-1}\right)\right) \cdot F_{s}\left(v_{s}\right) .
\end{aligned}
$$

Since $v_{b} \geq v_{s}$ and $v_{b-1} \leq v_{s+1}$, there exists a $p$ such that $v_{b-1} \leq$ $p \leq v_{b}$ and $v_{s} \leq p \leq v_{s+1}$, which shows that $q$ is posted price implementable.

The converse implication follows by definition of posted price implementation.

Remark. The result of Theorem 4.2(ii) also applies if $q$ ex postimplementable.

\section{Conclusion}

This paper provides a study of the bilateral trade model with discrete valuations. We focus on ex post individual rationality as the majority of research on this topic does not incorporate this stronger notion of individual rationality. Although potential players could be hesitant to participate in a mechanism that can leave them worse of compared to what they begin with. In order to illustrate the strength of our necessary condition, we investigate the class of threshold trading rules and find a close connection to posted price mechanisms.

Two interesting open questions are the following. How can ex post-implementation with quitting rights be characterized? Are ex post efficient trading rules also ex post-implementable for some strictly positive densities $f_{b}$ and $f_{s}$ ?

\section{Acknowledgements}

We would like to thank the Associate Editor and two anonymous referees for their valuable comments that helped to improve the quality of the paper considerably.

\section{Appendix}

Definition A.1. A direct mechanism $(q, t)$ is weakly incentive compatible (WIC) if

$U_{b}\left(b_{i}, b_{i}\right) \geq U_{b}\left(b_{i+1}, b_{i}\right)$ for all $i=1, \ldots, m-1$,

$U_{b}\left(b_{i}, b_{i}\right) \geq U_{b}\left(b_{i-1}, b_{i}\right)$ for all $i=2, \ldots, m$,

$U_{s}\left(s_{j}, s_{j}\right) \geq U_{s}\left(s_{j+1}, s_{j}\right)$ for all $j=1, \ldots, m-1$

$U_{s}\left(s_{j}, s_{j}\right) \geq U_{s}\left(s_{j-1}, s_{j}\right)$ for all $j=2, \ldots, m$.

A mechanism is weakly incentive compatible if no player has an incentive to misreport to those valuations adjacent to his own valuation. Clearly, any direct mechanism satisfying IC will also satisfy WIC. The following lemma shows that the converse is also true.

Lemma A.2. A direct mechanism $(q, t)$ is IC if and only if $(q, t)$ is WIC.

Proof of Lemma A.2. The "only if" part follows by definition of IC.

For the "if" part, we that no buyer wants to misreport to a higher valuation. A similar argument hold for misreporting to a lower valuation. Analogous for the seller.

Assume $(q, t)$ is WIC. For all $i=1, \ldots, m-1$,

$U_{b}\left(b_{i}, b_{i}\right) \geq U_{b}\left(b_{i+1}, b_{i}\right)$

$$
\begin{aligned}
= & U_{b}\left(b_{i+1}, b_{i+1}\right)+\left(b_{i}-b_{i+1}\right) \cdot \bar{q}_{b}\left(b_{i+1}\right) \\
\geq & U_{b}\left(b_{i}, b_{i+1}\right)+\left(b_{i}-b_{i+1}\right) \cdot \bar{q}_{b}\left(b_{i+1}\right) \\
= & U_{b}\left(b_{i}, b_{i}\right)+\left(b_{i+1}-b_{i}\right) \cdot \bar{q}_{b}\left(b_{i}\right) \\
& +\left(b_{i}-b_{i+1}\right) \cdot \bar{q}_{b}\left(b_{i+1}\right)
\end{aligned}
$$

and thus

$\bar{q}_{b}\left(b_{i}\right) \leq \bar{q}_{b}\left(b_{i+1}\right)$.

Let $b_{i} \in V_{b}$. We prove by induction that

$U_{b}\left(b_{i}, b_{i}\right) \geq U_{b}\left(b_{k}, b_{i}\right)$

for all $b_{k} \in V_{b}$ with $b_{k}>b_{i}$.

For the base case $b_{k}=b_{i+1}$, WIC directly implies that $U_{b}\left(b_{i}\right) \geq$ $U_{b}\left(b_{i+1}, b_{i}\right)$.

Assume that the induction step holds for $b_{k}<b_{m}$, then

$$
\begin{aligned}
U_{b}\left(b_{i}, b_{i}\right) & \geq U_{b}\left(b_{k}, b_{i}\right) \\
& =U_{b}\left(b_{k}, b_{k}\right)+\left(b_{i}-b_{k}\right) \cdot \bar{q}_{b}\left(b_{k}\right) \\
& \geq U_{b}\left(b_{k+1}, b_{k}\right)+\left(b_{i}-b_{k}\right) \cdot \bar{q}_{b}\left(b_{k}\right) \\
& \geq U_{b}\left(b_{k+1}, b_{k}\right)+\left(b_{i}-b_{k}\right) \cdot \bar{q}_{b}\left(b_{k+1}\right) \\
& =U_{b}\left(b_{k+1}, b_{i}\right)
\end{aligned}
$$

where the third inequality follows from $b_{k}>b_{i}$ and inequality (2). 
The following three lemmas are the discrete analogue of results in Myerson and Satterthwaite (1983).

Lemma A.3. Let $(q, t)$ be IC. Then for all $b_{i} \in V_{b}$ and all $s_{j} \in V_{s}$

$$
\begin{gathered}
U_{b}\left(b_{1}, b_{1}\right)+\sum_{k=1}^{i-1}\left(b_{k+1}-b_{k}\right) \cdot \bar{q}_{b}\left(b_{k}\right) \leq U_{b}\left(b_{i}, b_{i}\right) \\
\leq U_{b}\left(b_{1}, b_{1}\right)+\sum_{k=1}^{i-1}\left(b_{k+1}-b_{k}\right) \cdot \bar{q}_{b}\left(b_{k+1}\right), \\
U_{s}\left(s_{n}, s_{n}\right)+\sum_{\ell=j+1}^{n}\left(s_{\ell}-s_{\ell-1}\right) \cdot \bar{q}_{s}\left(s_{\ell}\right) \leq U_{s}\left(s_{j}, s_{j}\right) \\
\leq U_{s}\left(s_{n}, s_{n}\right)+\sum_{\ell=j+1}^{n}\left(s_{\ell}-s_{\ell-1}\right) \cdot \bar{q}_{s}\left(s_{\ell-1}\right) .
\end{gathered}
$$

Proof of Lemma A.3. Let us prove the left inequality of (3). The proofs of the other inequalities are analogous.

For all $i=1, \ldots, m-1$,

$$
\begin{aligned}
U_{b}\left(b_{i+1}, b_{i+1}\right)-U_{b}\left(b_{i}, b_{i}\right) & \geq U_{b}\left(b_{i}, b_{i+1}\right)-U_{b}\left(b_{i}, b_{i}\right) \\
& =\left(b_{i+1}-b_{i}\right) \cdot \bar{q}_{b}\left(b_{i}\right) .
\end{aligned}
$$

For each $b_{i} \in V_{b}$, adding all inequalities for $k=1, \ldots, i-1$ yields the desired result.

Lemma A.4. If a direct mechanism $(q, t)$ is IC, then

$U_{b}\left(b_{1}, b_{1}\right)+U_{s}\left(s_{n}, s_{n}\right) \leq u_{b}-l_{s}$.

Proof of Lemma A.4. Notice that

$$
\begin{aligned}
\sum_{i=1}^{m} & \sum_{j=1}^{n}\left(b_{i}-s_{j}\right) \cdot q\left(b_{i}, s_{j}\right) \cdot f_{b}\left(b_{i}\right) \cdot f_{s}\left(s_{j}\right) \\
= & \sum_{i=1}^{m} U_{b}\left(b_{i}, b_{i}\right) \cdot f_{b}\left(b_{i}\right)+\sum_{j=1}^{n} U_{s}\left(s_{j}, s_{j}\right) \cdot f_{s}\left(s_{j}\right) \\
\geq & \sum_{i=1}^{m}\left(U_{b}\left(b_{1}, b_{1}\right)+\sum_{k=1}^{i-1}\left(b_{k+1}-b_{k}\right) \cdot \bar{q}_{b}\left(b_{k}\right)\right) \cdot f_{b}\left(b_{i}\right) \\
& +\sum_{j=1}^{n}\left(U_{s}\left(s_{n}, s_{n}\right)+\sum_{\ell=j+1}^{n}\left(s_{\ell}-s_{\ell-1}\right) \cdot \bar{q}_{s}\left(s_{\ell-1}\right)\right) \cdot f_{s}\left(s_{j}\right) \\
= & U_{b}\left(b_{1}, b_{1}\right)+U_{s}\left(s_{n}, s_{n}\right)+\sum_{i=1}^{m-1}\left(b_{i+1}-b_{i}\right) \cdot\left(1-F_{b}\left(b_{i}\right)\right) \\
& \cdot \bar{q}_{b}\left(b_{i}\right)+\sum_{j=2}^{n}\left(s_{j}-s_{j-1}\right) \cdot F_{s}\left(s_{j-1}\right) \cdot \bar{q}_{s}\left(s_{j}\right),
\end{aligned}
$$

where the inequality follows from Lemma A.3. Rearranging the first and last term of these expressions yields the desired inequality.

Lemma A.5. Let $(q, t)$ be IC. Then

(a) the functions $\bar{q}_{b}\left(b_{i}\right), U_{b}\left(b_{i}, b_{i}\right)$ and $\bar{t}_{b}\left(b_{i}\right)$ are all non-decreasing in $b_{i}$.

(b) the functions $\bar{q}_{s}\left(s_{j}\right), U_{s}\left(s_{j}, s_{j}\right)$ and $\bar{t}_{s}\left(s_{j}\right)$ are all non-increasing in $s_{j}$.

Proof. IC implies WIC and thus by inequality $(2), \bar{q}_{b}\left(b_{i}\right)$ is nondecreasing in $b_{i}$. The proof of Lemma A.3 and $\bar{q}_{b}\left(b_{i}\right) \geq 0$ shows that $U_{b}\left(b_{i}, b_{i}\right)$ is non-decreasing in $b_{i}$. It remains to show that $\bar{t}_{b}\left(b_{i}\right)$ is non-decreasing in $b_{i}$. For all $i=1, \ldots, m-1$,

$$
\begin{aligned}
U_{b}\left(b_{i}, b_{i}\right)-U_{b}\left(b_{i+1}, b_{i}\right)= & b_{i} \cdot\left(\bar{q}_{b}\left(b_{i}\right)-\bar{q}_{b}\left(b_{i+1}\right)\right) \\
& +\bar{t}_{b}\left(b_{i+1}\right)-\bar{t}_{b}\left(b_{i}\right) \geq 0 .
\end{aligned}
$$

Since $\bar{q}_{b}\left(b_{i}\right) \leq \bar{q}_{b}\left(b_{i+1}\right)$ is non-decreasing in $b_{i}$, the above inequality implies that $\bar{t}_{b}\left(b_{i+1}\right)-\bar{t}_{b}\left(b_{i}\right) \geq 0$ and thus that $\bar{t}_{b}\left(b_{i}\right)$ is non-decreasing in $b_{i}$. The proofs for the seller are analogous.

The following lemma is the discrete analogue of a result in Gresik and Satterthwaite (1983).

Lemma A.6. If a direct mechanism $(q, t)$ is IC and IIR, then

$l_{s} \leq \sum_{i=1}^{m} \sum_{j=1}^{n} t\left(b_{i}, s_{j}\right) \cdot f_{b}\left(b_{i}\right) \cdot f_{s}\left(s_{j}\right) \leq u_{b}$.

Proof. Suppose $(q, t)$ is IC and IIR. We only show that

$\sum_{i=1}^{m} \sum_{j=1}^{n} t\left(b_{i}, s_{j}\right) \cdot f_{b}\left(b_{i}\right) \cdot f_{s}\left(s_{j}\right) \leq u_{b}$.

For each buyer with a valuation of $b_{i}$ for $i=2, \ldots, m$, IC implies

$\bar{t}_{b}\left(b_{i}\right)-\bar{t}_{b}\left(b_{i-1}\right) \leq b_{i} \cdot\left(\bar{q}_{b}\left(b_{i}\right)-\bar{q}_{b}\left(b_{i-1}\right)\right)$.

By adding all these inequalities for $k=2, \ldots, b$, we get

$\bar{t}_{b}\left(b_{i}\right)-\bar{t}_{b}\left(b_{1}\right) \leq \sum_{k=2}^{i} b_{k} \cdot\left(\bar{q}_{b}\left(b_{k}\right)-\bar{q}_{b}\left(b_{k-1}\right)\right)$.

By IIR, we have $\bar{t}_{b}\left(b_{1}\right) \leq b_{1} \cdot \bar{q}_{b}\left(b_{1}\right)$ and thus

$\bar{t}_{b}\left(b_{i}\right) \leq b_{1} \cdot \bar{q}_{b}\left(b_{1}\right)+\sum_{k=2}^{i} b_{k} \cdot\left(\bar{q}_{b}\left(b_{k}\right)-\bar{q}_{b}\left(b_{k-1}\right)\right)$.

Adding the inequalities of (5) over all $b_{i}$ and weighting by $f_{b}\left(b_{i}\right)$ yields

$$
\begin{aligned}
& \sum_{i=1}^{m} \sum_{j=1}^{n} t\left(b_{i}, s_{j}\right) \cdot f_{b}\left(b_{i}\right) \cdot f_{s}\left(s_{j}\right) \\
& \quad \leq b_{1} \cdot \bar{q}_{b}\left(b_{1}\right) \cdot f_{b}\left(b_{1}\right)+\sum_{i=2}^{m}\left(b_{1} \cdot \bar{q}_{b}\left(b_{1}\right)\right. \\
& \left.\quad+\sum_{k=2}^{i} b_{k} \cdot\left(\bar{q}_{b}\left(b_{k}\right)-\bar{q}_{b}\left(b_{k-1}\right)\right)\right) \cdot f_{b}\left(b_{i}\right) \\
& =\sum_{i=1}^{m}\left(b_{i} \cdot\left(1-F_{b}\left(b_{i-1}\right)\right)-b_{i+1} \cdot\left(1-F_{b}\left(b_{i}\right)\right)\right) \cdot \bar{q}_{b}\left(b_{i}\right) \\
& =u_{b} .
\end{aligned}
$$

This completes the proof.

Proof of Theorem 3.3. For the "only if" part, assume that $q$ is interim-implementable. By Lemma A.5, $\bar{q}_{b}\left(b_{i}\right)$ is non-decreasing in $b_{i}$ and $\bar{q}_{s}\left(s_{j}\right)$ is non-increasing in $s_{j}$. By Lemma A.6, $l_{s} \leq u_{b}$.

For the "if" part, assume that $\bar{q}_{b}\left(b_{i}\right)$ is non-decreasing in $b_{i}, \bar{q}_{s}\left(s_{j}\right)$ is non-increasing in $s_{j}$ and $l_{s} \leq u_{b}$. We will define a transfer scheme $t$ such that $(q, t)$ is IC and IIR. Define

$$
\begin{aligned}
t\left(b_{i}, s_{j}\right)= & b_{1} \cdot \bar{q}_{b}\left(b_{1}\right)+\sum_{k=2}^{i} b_{k} \cdot\left(\bar{q}_{b}\left(b_{k}\right)-\bar{q}_{b}\left(b_{k-1}\right)\right) \\
& -\sum_{\ell=1}^{j-1} s_{\ell} \cdot\left(\bar{q}_{s}\left(s_{\ell}\right)-\bar{q}_{s}\left(s_{\ell+1}\right)\right) \\
& +\sum_{\ell=1}^{n-1} s_{\ell} \cdot\left(1-F_{s}\left(s_{\ell}\right)\right) \cdot\left(\bar{q}_{s}\left(s_{\ell}\right)-\bar{q}_{s}\left(s_{\ell+1}\right)\right) .
\end{aligned}
$$


We show that $(q, t)$ is IC and IIR. Notice that all the three sums on the right-hand side are non-negative, due to our assumptions on $\bar{q}_{b}(\cdot)$ and $\bar{q}_{s}(\cdot)$. The first term is chosen so that $(q, t)$ satisfies incentive compatibility for the buyer, the second term so that $(q, t)$ satisfies incentive compatibility for the buyer and the third term so that $(q, t)$ satisfies $U_{b}\left(b_{1}, b_{1}\right)=0$ and $U_{s}\left(s_{n}, s_{n}\right) \geq 0$.

To check IC for the buyer, for $b_{i}, b_{i^{\prime}} \in V_{b}$ with $b_{i}>b_{i^{\prime}}$, we have $U_{b}\left(b_{i}, b_{i}\right)-U_{b}\left(b_{i^{\prime}}, b_{i}\right)=b_{i} \cdot\left(\bar{q}_{b}\left(b_{i}\right)-\bar{q}_{b}\left(b_{i^{\prime}}\right)\right)$

$$
\begin{aligned}
& -\left(\sum_{k=2}^{i} b_{k} \cdot\left(\bar{q}_{b}\left(b_{k}\right)-\bar{q}_{b}\left(b_{k-1}\right)\right)\right. \\
& \left.-\sum_{k=2}^{i^{\prime}} b_{k} \cdot\left(\bar{q}_{b}\left(b_{k}\right)-\bar{q}_{b}\left(b_{k-1}\right)\right)\right) \\
= & \sum_{k=i^{\prime}+1}^{i} b_{i} \cdot\left(\bar{q}_{b}\left(b_{k}\right)-\bar{q}_{b}\left(b_{k-1}\right)\right) \\
& -\sum_{k=i^{\prime}+1}^{i} b_{k} \cdot\left(\bar{q}_{b}\left(b_{k}\right)-\bar{q}_{b}\left(b_{k-1}\right)\right) \\
\geq & 0 .
\end{aligned}
$$

Similar if $b_{i}<b_{i^{\prime}}$.

To check IC for the seller, for $s_{j}, s_{j^{\prime}} \in V_{s}$ with $s_{j}<s_{j^{\prime}}$, we have

$$
\begin{aligned}
U_{s}\left(s_{j}, s_{j}\right)-U_{s}\left(s_{j^{\prime}}, s_{j}\right)= & -\sum_{\ell=1}^{j-1} s_{\ell} \cdot\left(\bar{q}_{s}\left(s_{\ell}\right)-\bar{q}_{s}\left(s_{\ell+1}\right)\right) \\
& +\sum_{\ell=1}^{j^{\prime}-1} s_{\ell} \cdot\left(\bar{q}_{s}\left(s_{\ell}\right)-\bar{q}_{s}\left(s_{\ell+1}\right)\right) \\
& -s_{j} \cdot\left(\bar{q}_{s}\left(s_{j}\right)-\bar{q}_{s}\left(s_{j^{\prime}}\right)\right) \\
= & \sum_{\ell=j}^{j^{\prime}-1} s_{\ell} \cdot\left(\bar{q}_{s}\left(s_{\ell}\right)-\bar{q}_{s}\left(s_{\ell+1}\right)\right) \\
& -\sum_{\ell=j}^{j^{\prime}-1} s_{j} \cdot\left(\bar{q}_{s}\left(s_{\ell}\right)-\bar{q}_{s}\left(s_{\ell+1}\right)\right) \\
\geq & 0
\end{aligned}
$$

Similar if $s_{j^{\prime}}<s_{j}$.

To check IIR, we have

$$
\begin{aligned}
U_{b}\left(b_{1}, b_{1}\right)= & b_{1} \cdot \bar{q}_{b}\left(b_{1}\right)-b_{1} \cdot \bar{q}_{b}\left(b_{1}\right) \\
& +\sum_{j=1}^{n} \sum_{\ell=1}^{j-1} s_{\ell} \cdot\left(\bar{q}_{s}\left(s_{\ell}\right)-\bar{q}_{s}\left(s_{\ell+1}\right)\right) \cdot f_{s}\left(s_{\ell}\right) \\
& -\sum_{\ell=1}^{n-1} s_{\ell} \cdot\left(1-F_{s}\left(s_{\ell}\right)\right) \cdot\left(\bar{q}_{s}\left(s_{\ell}\right)-\bar{q}_{s}\left(s_{\ell+1}\right)\right) \\
= & 0,
\end{aligned}
$$

and

$$
\begin{aligned}
U_{s}\left(s_{n}, s_{n}\right)= & \sum_{i=1}^{m}\left(b_{1} \cdot \bar{q}_{b}\left(b_{1}\right)+\sum_{k=2}^{i} b_{k} \cdot\left(\bar{q}_{b}\left(b_{k}\right)-\bar{q}_{b}\left(b_{k-1}\right)\right)\right) \\
& \cdot f_{b}\left(b_{i}\right)-\sum_{\ell=1}^{n-1} s_{\ell} \cdot\left(\bar{q}_{s}\left(s_{\ell}\right)-\bar{q}_{s}\left(s_{\ell+1}\right)\right) \\
& +\sum_{\ell=1}^{n-1} s_{\ell} \cdot\left(1-F_{s}\left(s_{\ell}\right)\right) \cdot\left(\bar{q}_{s}\left(s_{\ell}\right)-\bar{q}_{s}\left(s_{\ell+1}\right)\right) \\
& -s_{n} \cdot \bar{q}_{s}\left(s_{n}\right) \\
= & \sum_{i=1}^{m}\left(b_{i} \cdot\left(1-F_{b}\left(b_{i-1}\right)\right)-b_{i+1} \cdot\left(1-F_{b}\left(b_{i}\right)\right)\right) \cdot \bar{q}_{b}\left(b_{i}\right) \\
& -\sum_{j=1}^{n}\left(s_{j} \cdot F_{s}\left(s_{j}\right)-s_{j-1} \cdot F_{s}\left(s_{j-1}\right)\right) \cdot \bar{q}_{s}\left(s_{j}\right) \\
= & u_{b}-l_{s} \\
\geq & 0 . \quad \square
\end{aligned}
$$

\section{References}

Bulow, J., Roberts, J., 1989. The simple economics of optimal auctions. J. Polit. Econ. 97, 1060-1090.

Chatterjee, K., Samuelson, W., 1983. Bargaining under incomplete information. Oper. Res. 31, 835-851.

Coase, R., 1960. The problem of social cost. J. Law Econ. 3, 1-44.

Compte, O., Jehiel, P., 2009. Veto constraint in mechanism design: inefficiency with correlated types. Amer. Econ. J.: Microecon. 1, 182-206.

Forges, F., 1999. Ex post individually rational trading mechanisms. In: Current Trends in Economics: Theory and Applications. pp. 157-175.

Galavotti, S., Muto, N., Oyama, D., 2011. On efficient partnership dissolution under ex post individual rationality. Econom. Theory 48, 87-123.

Garratt, R., Pycia, M., 2016. Efficient Bilateral Trade. Mimeo.

Gresik, T., 1991a. Efficient bilateral trade with statistically dependent beliefs. J. Econom. Theory 53, 199-205.

Gresik, T., 1991b. Ex ante efficient, ex post individually rational trade. J. Econom. Theory 53, 131-145.

Gresik, T., Satterthwaite, M., 1983. The number of traders required to make a market competitive: the beginnings of a theory. In: Discussion Papers 551. In: Center for Mathematical Studies in Economics and Management Science, Northwestern University.

Hagerty, K., Rogerson, W., 1987. Robust trading mechanisms. J. Econom. Theory 42, 94-107.

Kos, N., Manea, M., 2009. Efficient Trade Mechanism with Discrete Values. Mimeo. Matsuo, T., 1989. On incentive compatible, individually rational, and ex post efficient mechanisms for bilateral trading. J. Econom. Theory 49, 189-194.

Matthews, S.A., Postlewaite, A., 1989. Pre-play communication in two-person sealed-bid double auctions. J. Econom. Theory 48, 238-263.

Myerson, R., 1981. Optimal auction design. Math. Oper. Res. 6, 58-73.

Myerson, R., Satterthwaite, M., 1983. Efficient mechanisms for bilateral trading. J. Econom. Theory 29, 265-281.

Othman, A., Sandholm, T., 2009. How Pervasive is the Myerson-Satterthwaite Impossibility? Mimeo.

Vohra, R., 2011. Mechanism Design: A Linear Programming Approach. Cambridge University Press. 